\title{
TINGKAT STRES LANSIA DENGAN PENYAKIT TIDAK MENULAR
}

\author{
Dian Aulia Kurniawati ${ }^{1 *}$, Mateus Sakundarno Adi $^{2}$, Rita Hadi Widyastuti ${ }^{1}$ \\ ${ }^{1}$ Program Studi Magister Keperawatan, Universitas Diponegoro, Jl. Prof. Soedarto, Tembalang, Kec. Tembalang, Kota \\ Semarang, Jawa Tengah, Indonesia 50275 \\ ${ }^{2}$ Fakultas Kesehatan Masyarakat, Universitas Diponegoro, Jl. Prof. Soedarto, Tembalang, Kec. Tembalang, Kota \\ Semarang, Jawa Tengah, Indonesia 50275 \\ *dianaulia4495@gmail.com
}

\begin{abstract}
ABSTRAK
Stres pada lansia dengan penyakit tidak menular merupakan masalah psikososial yang dapat mempengaruhi kualitas hidup dan kesejahteraan lansia apabila tidak segera diatasi, terutama dalam hal perawatan dirinya yang berpusat pada kepatuhan dalam pengobatan serta manajemen diri. Namun, penelitian yang membahas tentang tingkat stres pada lansia dengan penyakit tidak menular di wilayah kerja Puskesmas Pudakpayung Kota Semarang belum tersedia sehingga penelitian ini perlu dilakukan untuk melihat tingkat stres lansia dengan penyakit tidak menular: diabetes mellitus dan hipertensi. Penelitian menggunakan desain cross sectional dengan jumlah sampel 109 lansia dengan penyakit tidak menular yang didapatkan melalui teknik total sampling di wilayah kerja Puskesmas Pudakpayung di Kota Semarang pada tahun 2020. Kriteria inklusi dalam penelitian ini adalah lansia berusia 60 tahun keatas dengan penyakit tidak menular yaitu diabetes melitus dan hipertensi, menderita penyakit $\leq 5$ tahun. Instrumen yang digunakan dalam penelitian ini adalah Depresion, Anxiety, Stress Scale (DASS-42) berisi 14 pertanyaan, dengan tingkatan Discriminant validity dan mempunyai reliabilitas sebesar 0,8806 berdasarkan Cronbach Alpha. Hasil penelitian menunjukkan bahwa lansia dengan diabetes melitus sebagian besar mengalami stres sedang sebesar $62,7 \%$ dan lansia dengan hipertensi mengalami stres sedang sebesar $59,1 \%$.
\end{abstract}

Kata kunci: lansia, penyakit tidak menular, stres

\section{STRESS LEVELS IN ELDERLY WITH NON-COMMUNICABLE DISEASES}

\begin{abstract}
Stress in elderly with Non-communicable Diseases is an psychosocial problem that can affect the quality of life and well-being of the elderly if not immediately addressed, especially in terms of selfcare that is centered on adherence in medication and self-management. However, research that discusses about the levels of stress in elderly with non-communicable diseases in the working area of Pudakpayung's Public Health Centers in Semarang City is not yet available, so this research are needs to be done to look at the stress levels in elderly with non-communicable diseases : diabetes mellitus and hypertension. The study used a cross sectional design with 109 elderly with noncommunicable diseases to be a sample obtained through total sampling techniques in Pudakpayung's Public Health Centers in Semarang City on 2020. The criteria of inclusion in this study were the elderly aged 60 years and above with non-communicable diseases, suffering from illness $<5$ years. The instruments used in this study were Depression, Anxiety, Stress Scale (DASS42) contains 14 questions, with levels Discriminant validity and reliability have amounted to 0,8806 by Cronbach Alpha. The results showed that elderly with diabetes mellitus mostly experienced moderate stress by $62,7 \%$ and the elderly with hypertension experienced moderate stress by $59.1 \%$.
\end{abstract}

Keywords: elderly, non-communicable diseases, stress

\section{PENDAHULUAN}

Pada tahun 2016, sekitar 71 persen penyebab kematian di dunia adalah Penyakit Tidak Menular (PTM). Diabetes Mellitus (DM) Tipe 2 dan
Hipertensi masuk kedalam 10 besar penyakit tidak menular, dimana prevalensi paling tinggi penderita DM dan Hipertensi di dunia berada pada kelompok usia 65-79 tahun. 
Data dari hasil Riset Kesehatan Dasar (RisKesDas) pada tahun 2018 menunjukkan bahwa prevalensi DM pada lansia menduduki prosentasi tertinggi sebesar 36,6\% (Kemenkes RI, 2018). Menurut InfoDATIN Hipertensi tahun 2015 penduduk Indonesia yang menderita hipertensi sebanyak 25\% atau 65.048.110 jiwa (Info DATIN, 2015). Prevalensi DM dan Hipertensi di Jawa Tengah pada tahun 2018 mengalami peningkatan selama 5 tahun terakhir (Kemenkes RI, 2018). Diabetes yang tidak terkontrol dan faktor penyebab Hipertensi yang tidak teratasi akan memunculkan stres pada lansia, dan perubahan gaya hidup menjadi salah satu faktor penyebab munculnya stres pada lansia (Lueckenotte, 2000; Aljuaid, 2018).

Lansia dengan PTM yang mengalami stres akan cenderung mengalami kesedihan, tubuh menjadi lemah, berkurangnya nafsu makan dan minat dalam segala hal. Akibatnya akan mengalami keterlambatan dalam pengobatan. Jika kondisi ini dibiarkan berlarut-larut maka akan memicu timbulnya depresi. Selain itu, lansia akan kesulitan memotivasi dirinya untuk sembuh (Siregar \& Hidajat, 2017). Dampak stres pada lansia dengan PTM akan berpengaruh terhadap kualitas hidup dan kesejahteraan lansia dalam hal perawatan dirinya yang berpusat pada kepatuhan dalam pengobatan serta manajemen diri (Glover et al, 2016; Perrin et al, 2017). Teori Stres Adaptasi Stuart \& Laraia menjelaskan bahwa seseorang harus mempunyai mekanisme koping yang adaptif, sehingga lansia akan mampu untuk beradaptasi dengan faktor-faktor yang dapat menimbulkan stres/stressor (Stuart \& Laraia, 2009).

Diagnosis DM dan Hipertensi dapat membuat seseorang menjadi kehilangan kontrol. Kontrol yang buruk terhadap penyakit akan mengakibatkan komplikasi dan kematian lebih cepat. Stres pada penderita DM dan Hipertensi merupakan kumpulan tuntutan untuk hidup dengan normal. Klien harus bisa mengintegrasikan tuntutan dari penyakit menjadi keseharian (Ignatavicius \& Workman, 2006). Respon stres yang berlangsung secara berkelanjutan akan membuat tubuh mengalami gangguan diantaranya: Gangguan fisik (penyakit jantung, stroke, obesitas dan ulkus) dan gangguan psikologi (kecemasan, kemarahan dan agresi, apatis dan depresi serta gangguan kognitif) (Mardiana, 2014).
Penelitian yang dilakukan oleh Aprilia menunjukkan bahwa $49 \%$ lansia dengan hipertensi mengalami tingkat stres sedang (Aprilia, 2014). Penelitian yang dilakukan oleh Azizah dan Hartanti, menunjukkan bahwa sebagian besar lansia mengalami stres dalam kategori sedang. Hasil penelitian tersebut sejalan dengan teori yang menyatakan bahwa pada umumnya lansia akan mengalami stres, kecemasan dan depresi yang dapat mengakibatkan gangguan baik fisik, mental, maupun sosial (Azizah, 2016).

Berdasarkan hasil studi yang dilakukan didapatkan 109 lansia (perempuan 94 lansia dan laki-laki 15 lansia) yang berada di salah satu wilayah kerja Puskesmas di Kota Semarang, sebagian besar lansia tersebut menyatakan bahwa penyebab stres yang dialami adalah akibat beberapa faktor seperti penyakit yang diderita, kehilangan orang yang disayang, mengasuh cucu, kurangnya dukungan keluarga dan masalah ekonomi. Keluhan psikologis seperti mudah marah, terkadang merasa sedih, merasa tidak berdaya, merasa tidak berguna juga dirasakan oleh lansia. Stres menjadi salah satu masalah psikososial dimana tekanan hidup dan gaya hidup yang tidak sehat, serta berbagai penyakit yang sedang diderita dapat memicu terjadinya stres (Nugroho \& Purwanti, 2010). Akibatnya dari berbagai kumpulan tuntutan untuk hidup dengan normal, menyebabkan munculnya respon emosional/stres yang dapat menghambat proses terapi pada penderita PTM (Ignatavicius \& Workman, 2006; Isselbacher, 2000).

\section{METODE}

Penelitian ini dilakukan menggunakan desain cross sectional, terdiri dari 109 lansia yang didapatkan melalui teknik total sampling di wilayah kerja Puskesmas Pudakpayung Kota Semarang pada bulan Januari 2020. Kriteria inklusi dalam penelitian ini adalah lansia berusia 60 tahun keatas dengan PTM (Diabetes Mellitus dan Hipertensi), menderita penyakit $<5$ tahun. Lansia dengan PTM (Diabetes Mellitus dan Hipertensi) mengisi instrumen Depresion, Anxiety, Stress Scale (DASS-42) untuk mengetahui tingkat stres pada lansia dengan PTM. Uji validitas dan uji reliabilitas telah dilakukan pada Instrumen DASS-42 dengan hasil uji reliabilitas berdasarkan Cronbach Alpha sebesar 0,8806 pada masing-masing item yang terdiri dari 14 pertanyaan untuk mengukur depresi, ansietas dan stres, serta telah diuji cobakan di semua 
kalangan usia termasuk diantaranya adalah lansia (Randall et al, 2017). Uji etik penelitian dilakukan melalui Komisi Etik Penelitian Kesehatan Departemen Ilmu Keperawatan Fakultas Kedokteran Universitas Diponegoro dan dinyatakan lulus uji dengan nomor 80/EC/KEPK/D.Kep/II/2020.

Penilaian tingkat stres pada instrumen DASS-42 yang terdiri atas 14 pertanyaan, seseorang dikatakan normal apabila skor yang didapat adalah " $0-14$ ", stres ringan " $15-18$ ", stres sedang "19-25", stres berat "26-33", dan stres sangat berat " $>34$ ". Data yang didapatkan dianalisis menggunakan analisis statistik univariat untuk mengetahui dan mendiskripsikan gambaran pada masing-masing variabel yang terdiri dari umur, jenis kelamin, dan tingkat stres pada lansia penderita DM dan Hipertensi. Data-data tersebut ditampilkan dalam bentuk tabel distribusi frekuensi dan persentase.

\section{HASIL}

Hasil penelitian yang didapatkan dari pengisian instrumen DASS-42 berupa data deskriptif berupa data karakteristik dan tingkat stres pada lansia

Tabel 1

Gambaran Karakteristik Responden Berdasarkan Usia dan Jenis Kelamin ( $\mathrm{n}=109)$

\begin{tabular}{lcccc}
\hline & \multirow{2}{*}{ Variabel } & Diabetes Mellitus (DM) & \multicolumn{2}{c}{ Hipertensi } \\
\cline { 2 - 5 } & & & Jml & $\%$ \\
\hline Usia & 43 & 46,9 & 66 & 53,1 \\
60-74 tahun & & & & \\
Jenis Kelamin & 36 & 83,7 & 58 & 87,9 \\
$\quad \begin{array}{l}\text { Perempuan } \\
\text { Laki-laki }\end{array}$ & 7 & 16,3 & 8 & 12,1 \\
\hline Tabel 1 menunjukkan bahwa sebagian besar & adalah perempuan, sebanyak 36 lansia (83,7\%) \\
responden pada lansia dengan DM dan Hipertensi & pada penderita DM dan 58 lansia (87,9\%) pada \\
berada pada rentang usia 60-74 tahun. Jenis & penderita Hipertensi.
\end{tabular}

Tabel 2

Gambaran Tingkat Stres pada Lansia dengan PTM (n=109)

\begin{tabular}{lcccc}
\hline \multirow{2}{*}{ Variabel } & \multicolumn{2}{c}{ Diabetes Mellitus (DM) } & \multicolumn{2}{c}{ Hipertensi } \\
\cline { 2 - 5 } & Jml & $\%$ & Jml & $\%$ \\
\hline Tingkat Stres & & & & \\
Stres Ringan & 13 & 30,2 & 20 & 30,3 \\
Stres Sedang & 27 & 62,7 & 39 & 59,1 \\
Stres Berat & 3 & 7,1 & 7 & 10,6 \\
\hline
\end{tabular}

Tabel 2 menunjukkan hasil skrining tingkat stres pada lansia dengan PTM (DM dan Hipertensi), didapatkan hasil bahwa dari 43 lansia dengan DM dalam penelitian ini, sebanyak 13 lansia $(30,2 \%)$ mengalami stres ringan, 27 lansia $(62,7 \%)$ mengalami stres sedang, dan 3 lansia $(7,1 \%)$ mengalami stres berat. Hasil penelitian ini menunjukkan bahwa sebagian besar lansia dengan DM mengalami stres sedang sebesar $62,7 \%$. Lansia dengan Hipertensi menunjukkan hasil bahwa dari 66 lansia, sebanyak 20 lansia $(30,3 \%)$ mengalami stres ringan, 39 lansia $(59,1 \%)$ mengalami stres sedang, dan 7 lansia $(10,6 \%)$ mengalami stres berat. Hasil penelitian ini menunjukkan bahwa sebagian besar lansia dengan Hipertensi mengalami stres sedang sebesar $59,1 \%$.

\section{PEMBAHASAN}

\section{Usia}

Hasil penelitian ini menunjukkan bahwa usia lansia yang mengalami stres berada pada rentang usia 60-74 tahun. Hasil tersebut didukung penelitian oleh Scott, bahwa seseorang yang berusia di atas 56 tahun memiliki tingkat stres yang lebih tinggi dibandingkan seseorang yang berusia kurang dari 56 tahun, meskipun demikian lansia memiliki lebih sedikit efek negatif dalam hal emosional dari stres yang dialaminya (Scott et al, 2014). American Psycological Association 
(APA) menyatakan bahwa lansia memiliki tingkat stres namun tingkat stres yang dimiliki oleh lansia cenderung lebih rendah dibandingkan pada kelompok usia yang lain, dengan nilai presentasi tingkat stres pada lansia adalah 62\% (American Psycology Association, 2012). Stres yang dialami oleh lansia dalam penelitian ini dipengaruhi beberapa faktor, diantaranya: penyakit yang sedang diderita, kehilangan orang yang disayang, kurangnya dukungan keluarga, mengasuh cucu, serta masalah ekonomi.

\section{Jenis Kelamin}

Jenis kelamin lansia yang mengalami stres berdasarkan kuesiner yang diberikan terbanyak adalah perempuan, sebanyak 36 lansia $(83,7 \%)$ pada penderita DM dan 58 lansia $(87,9 \%)$ pada penderita Hipertensi. Alizadeh et.al dalam penelitiannya mengungkapkan bahwa perempuan beresiko 1,7 kali untuk mengalami stres dan depresi dibandingkan laki-laki (Alizadeh et al, 2012). Hal tersebut senada dengan hasil survey yang dilakukan oleh APA, bahwa perempuan memiliki tingkat stres yang lebih tinggi dibandingkan laki-laki, $23 \%$ perempuan melaporkan tingkat stres pada level 8,9 atau 10 (dengan skala maksimal 10), sedangkan pada laki-laki sedikit lebih rendah yaitu $16 \%$ (American Psycological Association, 2012).

\section{Tingkat Stres}

Hasil penelitian menunjukkan bahwa sebagian besar lansia menderita stres sedang. Lansia dengan PTM yang mengalami stres sedang disebabkan karena lansia sering mengalami mudah tersinggung, mudah marah karena hal-hal sepele seperti ketika cucu mereka rewel dan tidak bisa diatur, sulit bersantai, mudah gelisah, dan tidak sabar ketika mengalami penundaan. Menurut Musradinur, individu sering menggunakan keadaan emosionalnya untuk mengevaluasi stres. Reaksi emosional terhadap stres antara lain: kecemasan, depresi, perasaan sedih dan rasa marah. Dampak negatif stres yaitu tekanan darah tinggi, pusing, sulit berkonsentrasi, sedih, tidak bisa tidur seperti biasanya, dan depresi (Musradinur, 2016).
Respon stres yang muncul akibat stres yaitu adanya sekresi hormon yang berlebihan kedalam aliran darah, peningkatan frekuensi kerja jantung dan pernapasan serta respon fisik lainnya (American Psycological Association, 2010). Beberapa penelitian membuktikan bahwa lansia yang mengalami stres memperbesar risiko untuk mengalami kecacatan dan gangguan aktivitas sehari-hari, terjadi gangguan kesehatan seperti peningkatan risiko penyakit arteri koroner dan penurunan kesejahteraan kualitas hidup lansia (Lavretsky, 2012; American Psycological Association, 2010).

Menurut penelitian yang dilakukan oleh Dahroni dkk, lansia yang mengalami stres emosi seperti rasa khawatir dengan masalah yang tidak jelas, merasa letih, merasa capek, dan jantung berdebar akan menyebabkan kualitas tidur yang menurut. Lansia yang mengalami stres akan mengalami kualitas tidur yang buruk. Depresi dan kecemasan seringkali mengganggu tidur. Kecemasan akan meningkatkan kadar norepinephrin dalam darah akan merangsang sistem saraf simpatik yang menimbulkan fungsi tubuh tidak normal (Dahroni \& Arisdiani, 2017). Dalam hal ini, manajemen stres sangat diperlukan pada lansia dengan stres PTM, agar DM dan Hipertensi dapat terkontrol sehingga tidak memperparah kondisi penyakitnya. Perawat komunitas memiliki peran terhadap penanganan stres pada penderita lansia dengan PTM, salah satu perannya adalah dengan memberikan upaya kuratif melalui pendekatan Non farmakologi (RI MK, 2009). Selain itu, perawat komunitas menjalankan perannya untuk melakukan tindakan promotif dan preventif kesehatan guna melindungi kesehatan lansia melalui ilmu dan keterampilan yang dimiliki untuk mengatasi masalah yang dihadapi oleh lansia (Efendi \& Makhfuldli, 2009). Intervensi yang dapat diberikan untuk mengatasi stres pada lansia dengan PTM antara lain: peningkatan sistem dukungan, peningkatan koping, dan terapi kelompok (Bulechek et al, 2013).

\section{SIMPULAN}

Tingkat stres pada lansia dengan PTM (Diabetes Mellitus dan Hipertensi) di salah satu wilayah 
kerja Puskesmas Kota Semarang mengalami stres sedang. Stres pada lansia dengan PTM perlu untuk segera diatasi, agar tidak berdampak buruk terhadap kesehatan fisik ataupun psikologis lansia sehingga, kualitas hidup lansia akan meningkat.

\section{DAFTAR PUSTAKA}

Alizadeh M, Hoseini M, Shojaeizadeh D, Rahimi A AM. (2012) 'Assessing anxiety, depression and psychological wellbeing status of urban elderly under represent of Tehran Metropolitan City', Asian J Aging, 7(3):66-73.

Aljuaid, M. O. E al. (2018) 'Diabetes-Related Distress Assessment among Type 2 Diabetes Patients', J Diabetes Res Hindawi,Volume 201.

American Psycology Association. (2012) 'Generation stress at any age is still stress'.

American Psycology Association. (2012) 'Stres by Gender', stressinamerica.org.

American Psycology Association. (2010) 'Coping With Stress and Anxiety'.

Aprilia DD. (2014) 'Gambaran Tingkat Stres pada Lansia yang Mengalami Hipertensi di Wilayah Kerja Puskesmas Gedangan Sidoarjo', Unusa Repos, http://repository.unusa.ac.id/id/eprint/883.

Azizah R HRD. (2016) 'Hubungan antara Tingkat Stres dengan Kualitas Hidup Lansia Hipertensi di Wilayah Kerja Puskesmas Wonopringgo Pekalongan', 4 th Univ Res Coloqium 261278.

Bulechek, G. M., Butcher, H. K., Dochterman, J, M., Wagner CM. (2013) 'Nursing Intervention Classivication (nic)', 6th Ed Oxford Elsevier.

Dahroni, Arisdiani T WY. (2017) 'Hubungan antara stres emosi dengan kualitas tidur lansia', J Keperawatan, 5 (2): 68.

Efendi, F., Makhfuldli M. (2009) 'Keperawatan Kesehatan Komunitas: Teori dan Praktik Dalam Keperawatan-Google Book', Jakarta Salemba Med.

Glover, C.M., Wang, Y., Fogelfeld, L., Lynch EB. (2016) 'Stress and other determinants of diabetes-specific quality of life in low- income African Americans with uncontrolled type 2 diabetes mellitus', J Heal Care Poor Underserved Publ by Johns Hopkins Univ Press Doi https//doi.org/101353/hpu20160142,

Volume 27.

Ignatavicius, D. D., \& Workman ML. (2006) 'Medical Surgical Nursing: Critical Thinking for Collaborative Care', (5th). Philadelphia: Elsevier Saunders.

Info DATIN (Pusat Data Dan Informasi Kementrian Kesehatan RI). (2015) 'Hipertensi'.

Isselbacher KJ. (2000) 'Harrison Prinsip-Prinsip Ilmu Penyakit Dalam', (13th) Vol 5 AH Asdie, Terj Jakarta EGC.

Kemenkes RI. (2018) 'Hasil utama Riskesdas 2018', Kemenkes RI Badan Penelitian dan Pengembangan Kesehatan.

Lavretsky H NP. (2012) 'Stress, inflammation, and aging', Am J Geriatr Psychiatry, 20(9):729-733. doi:10.1097.

Lueckenotte AG. (2000) 'Gerontologic Nursing', 2nd Ed Mosby St Louis, Missouri, Philadelphia.

Mardiana Y. (2014) 'Hubungan Antara Tingkat Stres Lansia dan Kejadian Hipertensi Pada Lansia', J Forum Ilm, 11(2):261.

Musradinur. (2016) 'Stres dan cara mengatasinya dalam perspektif psikologi', J Edukasi, 2 (2): 183.

Nugroho, A. S. \& Purwanti SO. (2010) 'Hubungan antara tingkat stres dengan kadar gula darah pada pasien diabetes mellitus di wilayah kerja Puskesmas Sukoharjo I Kabupaten Sukoharjo', EJournal FIK UMS.

Perrin, N. E., Davies, M.J., Robertson, N., Snoek, F.J., Khunti K. (2017) 'Systematic review or meta-analysis the prevalence of diabetesspecific emotional distress in people with type 2 diabetes: a systematic review and meta-analysis", Diabet Med UK Doi 101111/dme13448.

Randall D, Thomas M, Whiting D MA. (2017) 'Depression Anxiety Stress Scales (DASS- 
42)', J Head Trauma Rehabil, 32(2)134144 doi101097/HTR0000000000000250.

RI MK. (2009) 'Undang-Undang Republik Indonesia No. 36 Tahun 2009 tentang kesehatan', Jakarta Menteri Kesehat RI.

Scott SB, Sliwinski MJ, Mogle JA AD. (2014) 'Age, stress , and emotional complexity: results from two studies of daily experiences', Am Psychol Asoc, 29(3):577587.

Siregar, L. B. dan Hidajat LL. (2017) 'Faktor yang berperan terhadap depresi, kecemasan dan stres pada penderita diabetes melitus tipe 2: studi kasus Puskesmas Kecamatan Gambir Jakarta Pusat', J Ilm Psikol MANASA, Vol 6, No 1, 15-22.

Stuart, G. W., \& Laraia M. (2009) 'Principle and practice of psyciatric nursing (9th edition)'. 